\title{
Effect of Educational Program for Cardiopulmonary Resuscitation Using Simman versus TraditionalManikin on 2nd Year Nursing Students' Performance
}

\author{
Eman El. Allah ${ }^{1}$, Kamelia F.Abd-Allah², Mahmoud Abd El Sapour ${ }^{3}$, \\ Sabah S. Mohammed ${ }^{4}$ \\ ${ }^{1}$ Clinicalinstructor at Benha technical health institute \\ ${ }^{2}$ Professor of Med-Surgical Nursing, Faculty of Nursing, Ain shams Univeristy. \\ ${ }^{3}$ Professor of Microbial,Faculty of medicine Benha University \\ ${ }^{4}$ Lecturer of Medical surgical nursing, Faculty of Nursing, Benha University \\ E-mailsabah.abdlrazek@fnur.bu.edu.eg
}

\begin{abstract}
:
Aim: of this study is to evaluate the effect of educational program for cardiopulmonary resuscitation (CPR) using SimMan versus traditional manikin on $2^{\text {nd }}$ year nursing student's performance at Medical Surgical Nursing Department laboratory- Faculty of Nursing -Benha University.

Research hypothesis: The mean score of $2^{\text {nd }}$ year nursing students' performance level regarding CPR in the study group will be higher than the score of students in the control group.

Design:A quasi-experimental researchwas utilized.

Setting: This study was conducted in Medical Surgical Nursing Department laboratory- Faculty of Nursing Benha University.

Subject:All available $2^{\text {nd }}$ year nursing students (340 students) were recruited in this study and divided into equal groups, the control group using the traditional manikin and a study group using SimMan.

Tools:Data were collected through two main tools: Nursing students' self-administered questionnaire sheet to assess students' general characteristics and knowledge regardingCPR. And nursing students' practice observational checklist for $C P R \& A E D$ to assess students' practice regarding $C P R$.

Results:mean scores of students' knowledge and practice regarding advancedCPR in study group was higher than control group $(P<0.001)$.There was positive correlation betweenstudents'total knowledge andpractice scores in both groups.

Conclusion: there was a highly statistically significant improvement in nursing students' performance level regarding advanced CPR using SimMan versus traditional manikin.

Recommendation:Additional researches need to be conducted on the use of SimMan for improving nursing education, critical thinking, and clinical competency and evaluate its effect on the students' performance regarding CPR on the actual patients (in the real situations) with cardiac arrest in emergency departments

Keywords: Cardiopulmonary resuscitation,Nursing education,Performance,SimMan.
\end{abstract}

\section{Introduction}

Nursing education has long utilized simulation in some form to teach principles and skills of nursing care. Simulation in nursing education in the form of static manikins, role playing, CPR manikins, and other techniques has also been utilized as a teaching modality for quite some time. Nursing education needs to play its key role in training innovative, committed and responsible students so that, the students can effectively take different roles and critical nursing duties in different situations ${ }^{[1]}$.

The developments in medical technology and the increasing number of severe cases, advanced intensive expertise and nursing intervention techniques are required in the clinical field. Therefore, nurses are required to have more sophisticated work capacities. Through theoretical and practical educational programs, nursing education organizations focus on nurturing professional nurses' abilities to provide high-quality services. Simulation in nursing education has been recommended and introduced ${ }^{[2] .}$

Simulation is defined as a technique used to "replace or amplify real experiences with guided experiences that evoke or replace substantial aspects of the real world in a fully interactive manner.Medical simulators range from simple replications of body parts for task based learning of some examination skills, to more sophisticated HFHPS driven by complex pathophysiological computer models which are developed to replicate clinical environments ${ }^{[3]}$.SimMan is manikin utilized in resuscitation training have realistic features such as the ability to replicate chest expansion and breathing sounds, provide exhaled carbon dioxide, generate a pulse and blood pressure, and speak or make sounds. SimMan measures the quality of CPR providing realtime feedback regarding compression rate, depth, release, and hands-off time. In addition, SimMan can respond 
appropriately to treatment; it automatically registers the amount, speed, and type of drug and activates the appropriate physiological responses ${ }^{[4]}$.

The CPR is an essential skill for all health care professionals, especially nurses. It can be a lifesaver when applied by a competent and skilled person during resuscitation. The CPR procedure is a coordinated integration of chest compression-induced circulation, rescue airway and breathing management whereby priorities are determined by evidence from literature and practice and required professional and good training nurses ${ }^{[4]}$.

\section{Aim Of The Study}

The aim of the study is to evaluate the effect of educational program for cardiopulmonary resuscitation (CPR) using SimMan versus traditional manikin on $2^{\text {nd }}$ year nursing students' performance through the following:

1- Assessment of 2nd year nursing students' performance level (knowledge and practice) in both groups (study \& control) regarding CPR pre educational program implementation using SimMan versus traditional manikin.

2- Designing and implementing educational program regarding CPR for 2nd year nursing students using SimMan versus traditional manikin.

3- Evaluating the effect of educational program regarding CPR using SimMan versus the traditional manikin on 2nd year nursing students' performance (knowledge and practice).

Research hypothesis

The mean score of $2^{\text {nd }}$ year nursing students' performance level (knowledge and practice) regarding CPR in the study group will be higher than the score of students in the control group post program implementation.

Research Design: A quasi-experimental research design was utilized to conduct the aim of this study.

Setting:

This study was conducted at Medical Surgical Nursing Department laboratory- Faculty of Nursing -Benha University.

\section{Subjects:}

All available $2^{\text {nd }}$ year nursing students (340 students) in academic year (2014-2015) were recruited in this study applying two the clinical teaching methods. The subject was randomly divided equally into study group (170) and control group (170).Using the traditional manikin for the control group, while using SimMan for the study group.

Tools of data collection:Data were collected through two main tools:

First tool: Nursingstudents'Self-administeredquestionnaire sheet:

It was constructed by the researcher after reviewing relevant literature. It was written for assessing $2^{\text {nd }}$ year nursing students' knowledge regarding CPR in both groups (study \& control), it included:

Part (1):Demographic characteristics of $2^{\text {nd }}$ year nursing students in both groups such as: name, age, gender, group, educational level, learning experiences and number of training program.

Part (2): (A) students' knowledge regarding CPR:It was included meaning of cardiac arrest, signs and symptoms of cardiac arrest, first aid for cardiac arrest,principles, indication, main components for CPR according to priority, the ways to open the air way, the steps to give the victim breaths, the way to check the breathing, depth of chest compression, the rate of compressions, the site at which starts chest compressions, contraindication and complications of CPR. It contained (21) questions which designed by the researcher and adopted from previous research references after reviewing related literature.

(B): Students' knowledge regarding Automatic External Defibrillator (AED):It was included meaning of AED, characteristics of AED, indications, what should be indicated if shock present, contraindications, complication of defibrillation and post defibrillation nursing care. It contained (9) questions.

\section{Knowledge scoring system:}

All knowledge variables were weighted according to the items included in the model answer of each question. The data collected from the knowledge test was computed and the test received a grade out of 21questions for CPR and 9 questions for AED, the scores were allocated as follows: right (1) and wrong (0).

The score of knowledge test expressed as percent from a maximum of 30 points as follow:

$\geq 70 \%$ (22 points) considered satisfactory level of knowledge.

$<70 \%$ (22 points) considered unsatisfactory level of knowledge.

Second tool: Nursing students' practice observational checklist;it included the following:

Part(1): Nursing students' practice observational checklist for CPR:

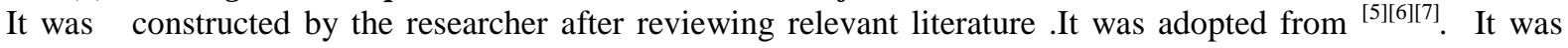
concerned with assessing the nursing students' practice regarding CPR in both groups (study \& control). The items of the checklist were checked as done correct, done incorrect or not done. This part consisted of (24) items that identify the steps of CPR, it was contained the following items: 
Pre procedure :( 5 items) it included hand washing, wearing gloves, preparing equipment, keeping privacy and assess the patient condition.

During procedure: (13 items) it included noting time of arrest, assessing patient's consciousness by taping him on the shoulder and shout" are you alright", checking for responsiveness and assess Air way, Breathing and Circulation to see if the patient is apnea or gasping, immediately calling out for help, palpating the carotid artery during 10 seconds after arrest, placing the patient supine on a firm surface, while rolling his head and torso as a unit, removing bed head if patient is in bed and ensuring adequate space between back of bed and wall, ensuring a clear air way, giving 30 chest compressions, opening the airway, delivering breathing, maintaining intubation and establishing intravenous access.

Post procedure: (6 items) it was included; assessing the patient's condition (airway, breathing, circulation, blood pressure and urine output),checking arterial blood gases, checking full blood count andbiochemistry, monitoring patient's cardiac rhythm and recording 12- lead of ECG and assessing patient's level of consciousness.

Part (2): Nursing students' practice observational checklist for AED:

It concerned with the assessing the nursing students' practice regarding the AED procedure in both groups. It consisted of 21 items, it included verifying that patient is unresponsive, verifying ECG reading of ventricular tachycardia, or ventricular fibrillation, checking that crash cart has arrived or begin CPR, pluging defibrillator into electric outlet, turning defibrillator power on and defaults to 200 joules, preparing patient and/or paddles with proper conductive agent, checking that defibrillator is in asynchronous mode, turning on ECG recorder for continuous printout, turning off oxygen source during actual, standing away from bed area. Also, it included placing one paddle at the heart's Apex just left of the nipple in midaxillary line, placing the other paddle just below the right clavicle to the right of the sternum, applying paddles with firm pressure $(11 \mathrm{~kg}$ pressure), depressing discharge buttons on defibrillator simultaneously to ensure appropriate discharge, delivering 3 stacked shocks (if necessary) in close sequence (200 J, 250-300) or according to doctor order, resuming CPR immediately, beginning with chest compression (giving five cycle), assessing patient cardiac rhythm, continuing CPR, initiating advanced life support protocols, intubation and obtaining IV access, , post procedure including care of patient, care of the used equipment and documentation.

Practice scoring system; each item was scored as follows:

- $\quad$ Zero =not done.

- $\quad(1)=$ done incorrectly.

- $\quad(2)=$ done correctly.

The total scores were (46) for CPR, (42) for AED and total scores (88) as follows;

$\geq 80 \%$ (70 points) considered satisfactory level of students' practice.

$<80 \%$ (70 points) considered unsatisfactory level of students' practice

Preparatory phase:

This phase included the following; reviewing the available literature and different studies related to research problem, and theoretical knowledge of its various aspects of the study, using textbooks, evidence-based articles, internet periodicals and magazines in order to collect tools of this study. This period extended from February 2014 to June 2014.

\section{Designing the educational program:}

This was taken period of time from June 2014 to August 2014. Based on literature review, the researcher designed educational program regarding CPR for $2^{\text {nd }}$ year nursing students using SimMan versus traditional manikin At Medical Surgical Nursing Department laboratory- Faculty of Nursing -Benha University. The designed educational program regarding CPR was developed and constructed by the researcher in the form of booklet. The booklet consisted of two parts;

Theoretical part covered the knowledge related to cardiac and respiratory arrest (definition, pathophysiology, causes, diagnosis and signs \& symptoms). Knowledge about CPR (definition, indications, principles,phases, complications, advanced technique for airway managementand drugs used). Knowledge about defibrillation(indication, purpose, equipment, precautions andtypes).Knowledge related to AED (Paddle placement, Precautions, Complications, Disadvantage).

Practical part: related to CBR and AED procedure included definition, purpose, principles, indication, CPR procedure guide line steps and AED procedure guide line steps.

Tools validity and reliability

Validity:Testing validity was tested byan expert panel consisting of 9 experts who composed of 1 professor, 1 assistant professor and 1 lecturer from faculty of nursing,Zgazig University, 2 assistant professors and 1 lecturer from faculty of nursing,Benha University, 1 professor, 1 assistant professor and 1 lecturer from faculty of medicine,Benha University .Testing reliability of the proposed tools was done by Cronbach alpha test.

\section{A Pilot study}


Pilot study was carried out on $10 \%$ of the studied subjects(37 students). Some questions and items were omitted, added or rephrased, and then the final forms were developed the experts reviewed the tools for clarity, relevance, comprehensiveness and simplicity \& applicability. The students included in pilot study were excluded from main study subjects. This phase took one month.

\section{Ethical consideration:}

Approval was granted for this study by the faculty of nursing ethical committee before implementation the educational program. The researcher assured maintaining anonymity and confidentiality of the subjects' data.The nursing students were informed that they are allowed to choose to participate or not in the study and they had right to withdraw from the study at any time. The research tools were not causing any harm or pain for the nursing students. The researcher clarified the purpose, requirements, duration and anticipated benefits of the study to the nursing students.

Field work:

The process of data collection was carried out from $7 \backslash 2 \backslash 2015$ to 20\4\2015. The researcher interviewed the students in both study and control groups in the academic year (2014-2015) and started the educational program by teaching the theoretical part about advanced CPR for all students in both groups. Theoretical part conducted in the $2^{\text {nd }}$ year medical surgical nursing students' department class room and took 2 hours but regarding implementation the practical part conducted in the affiliated laboratory to this department and took 4 hours for each group including demonstration and re-demonstration for 10 days. For the students in the control group the academic staff that was responsive for these students (170) were oriented about the check list that was developed by the researcher to be used for training and evaluating them. After that the students in control group were divided into 10 groups, the number of the students in each group was (17) students. Then the academic staff does demonstration using traditional manikin and allow them to do re-demonstration; this training phase took 10 days. Meanwhile the students in study group were divided into 20 groups the number of the students in each group was (8 or 9) students to facilitate their training on the SimMan according to the stated scenario. SimMan is a wireless life size patient manikin that can talk with pre-recorded sounds and speech, breathe with normal and abnormal breath sounds and produce heart sounds, palpable pulses and unilateral/ bilateral chest movements. It is connected to a monitor which displays parameters such as oxygen saturation, ECG trace, pulse rate and blood pressure. It can be programmed with a range of clinical examination findings, in current study it was programmed to display up signs of cardiac arrest.SimMan was set up on a standard hospital bed equipped with monitors, simulated oxygen supply and other supplies found in the clinical skills lab such as a training automatic external defibrillator, oxygen, medications, an oropharyngeal airway and a bag-mask manual ventilator. The researcher was started the evaluation phase after the end of re- demonstration phase for all the students in the study and control groups. Each student was evaluated 3 times ( 3 trials) and the mean was taken. The time of evaluation for each student in each trial took about 15 to 20 minutes. The evaluation phase took one month, during this period the researcher observed the students' practice for CPR through the observational check list and assessed their knowledge through nursing students' selfadministered questionnaire sheet.

NB: The final evaluation was documented for $2^{\text {nd }}$ year nursing students in the control group after the exposure to the same experience and calculated average of their mean scores to avoid bias in the difference of practice mean scores between both groups regarding CPR procedure.

\section{Administrative Design:}

Approval to carry out this study was granted from the Dean of Faculty of Nursing, Benha University, and Head of medical surgical nursing department. The researcher was visited the setting and done interview with the nursing students to explain the objectives and the nature of the study and then carry out the study with minimum resistance.

\section{Statistical Design:}

The collected data were organized, coded, computerized, tabulated and analyzed by using the statistical package for social science (SPSS), version (11). Data analysis was accomplished by the use of number, percentage distribution, mean, standard deviation, and correlation, coefficient, Paired t-test and multiple linear regression analyses was used to test the significance of some variances. A significant level value was considered when $\mathrm{p}<0.05$.

\section{Results}

Table (1): This table demonstratesdistribution of demographic characteristics among studied students, that the majority of the studied groups (control and study) were females with mean age (20.2588 $\pm .8 \& 20.0235 \pm .687$ ) respectively and there was no statistically significant different between control and study groups regarding demographic characteristics $(\mathrm{P}>0.05)$.

Table (2): This table demonstrated the mean score of studied students' total knowledgeregarding cardiac arrest, CPR and AED, there was highlystatistically significant difference between control and study groups with $\mathrm{P}<0.001$. 
Table (3): This table demonstratedcomparison between the mean score of students' total practice regarding CPR \& AED during the three trial of evaluation in both study and control groups, there was highlystatistically significant differences in both control and study groups with $\mathrm{P}<0.001$. Whereas, the mean score of students' total practice during third trial $(126.494 \pm 4.07801)$ was more than the mean score of their total practice during first and second trials respectively $(112.470 \pm 6.85624 \& 121.776 \pm 3.71906)$ for the study group.

Table (4): This table illustrated the statistically significant relation between mean score of students' total knowledge regarding CPR and age in both control \& study groups with $\mathrm{P}<0.05$. while there was no statistically significant relation between mean score of their total knowledge and gender in both control \& study groups with $\mathrm{P}>0.05$.

Table (5): This table showed that no statistically significant relation between mean score of students' total practice regarding CPR and demographic characteristics in both control and study groups with $\mathrm{P}>0.05$.

Table (6): This table cleared positive correlation between students' total practice score and total knowledge score in both control and study groups' $\mathrm{p} \leq 0.001$.

Table (1): Description of demographic characteristics among the studied students in both the study \& control groups.

\begin{tabular}{|c|c|c|c|c|c|c|}
\hline \multirow{3}{*}{ Demographic characteristics } & \multirow{2}{*}{\multicolumn{2}{|c|}{$\begin{array}{l}\text { Control } \\
(\mathbf{n}=170)\end{array}$}} & \multirow{2}{*}{\multicolumn{2}{|c|}{$\begin{array}{l}\text { Study } \\
(n=170)\end{array}$}} & \multirow{3}{*}{$\begin{array}{l}\text { Chi- } \\
\text { square } \chi^{2}\end{array}$} & \multirow{3}{*}{$\begin{array}{l}\mathbf{P} \\
\text { Value }\end{array}$} \\
\hline & & & & & & \\
\hline & No & $\%$ & No & $\%$ & & \\
\hline \multicolumn{5}{|l|}{ Age in years } & \multirow{4}{*}{3.71} & \multirow{4}{*}{$>0.05$} \\
\hline $19-20$ & 114 & 67.1 & 130 & 76.5 & & \\
\hline $20-23$ & 56 & 32.9 & 40 & 23.5 & & \\
\hline Mean \pm SD & \multicolumn{2}{|c|}{$20.26+0.816$} & \multicolumn{2}{|c|}{$20.02+0.687$} & & \\
\hline \multicolumn{5}{|l|}{ Gender } & \multirow{3}{*}{0.325} & \multirow{3}{*}{$>0.05$} \\
\hline Female & 145 & 85.3 & 141 & 82.9 & & \\
\hline Male & 25 & 14.7 & 29 & 17.1 & & \\
\hline \multicolumn{5}{|l|}{ Educational level } & \multirow{3}{*}{1.65} & \multirow{3}{*}{$>0.05$} \\
\hline Secondary school & 111 & 65.3 & 122 & 71.8 & & \\
\hline Technical institute & 59 & 34.7 & 48 & 28.2 & & \\
\hline
\end{tabular}

No statistically significant at $(\mathrm{p}>0.05)$

Table (2): The mean score of students' total knowledge regarding cardiac arrest, CPR and AED in both study \& control groups

\begin{tabular}{|c|c|c|c|c|c|c|c|}
\hline \multirow[t]{2}{*}{ Enowledge } & \multicolumn{2}{|c|}{ Control $(u=170)$} & \multicolumn{3}{|c|}{ Studț $(1=170)$} & \multirow{2}{*}{$\begin{array}{l}\text { Independent } \\
\text { t test }\end{array}$} & \multirow{2}{*}{ Pralue } \\
\hline & Yean & $\pm S D$ & Mean & \pm & SD & & \\
\hline Total Knoriledge related to Cardiac arrest. & 2,4471 & $=.73791$ & 2.7294 & \pm & 56292 & -3.967 & $\$ 0.0001^{\mathrm{kx}}$ \\
\hline Total Knowledge related to CPR. & 9.9765 & $=2.39069$ & 11.6235 & \pm & 1.63885 & -7.409 & 4).0001 $1^{8 *}$ \\
\hline Total Knomledge related to AED. & 6.0176 & $=1.86679$ & 7.5412 & \pm & 1.32391 & 8.680 & $40.0001^{k *}$ \\
\hline Total knowledge. & 18.4412 & $=4.04700$ & 21.8941 & $=$ & 2.43507 & -9.532 & $4.0001^{* *}$ \\
\hline
\end{tabular}

Highly statistically significant at $\left(\mathrm{p}<0.001^{* *}\right)$

Table (3): Comparison between the mean score of students' total practice regarding CPR \& AED during the three trial of evaluation in study and control groups

\begin{tabular}{|c|c|c|c|c|c|c|c|c|}
\hline \multirow[t]{2}{*}{ Time of assessment } & \multirow{2}{*}{ procedure } & \multicolumn{3}{|c|}{ Control $(\mathrm{n}=170)$} & \multicolumn{2}{|c|}{ Study $(\mathrm{n}=170)$} & \multirow{2}{*}{$\begin{array}{l}\text { Independent } \\
\text { t test }\end{array}$} & \multirow{2}{*}{ P value } \\
\hline & & Mean & \pm & SD & Mean & $\pm \mathrm{SD}$ & & \\
\hline \multirow{3}{*}{ First trail } & CPR & 46.858 & \pm & 7.65321 & 68.8176 & $=5.89822$ & -29.631 & $<0.001^{8 * x}$ \\
\hline & AED & 31.894 & \pm & 3.70518 & 43.6529 & $=2.58412$ & -33.940 & $<0.001^{* * *}$ \\
\hline & Total & 78.752 & \pm & 8.12536 & 112.470 & $=6.85624$ & -41351 & $<0.001^{* * *}$ \\
\hline \multirow{3}{*}{ Second trail } & $\mathrm{CPR}$ & 63.158 & \pm & 5.82624 & 76.4412 & $=3.09983$ & -26.241 & $4.001^{* *}$ \\
\hline & AED & 40.211 & \pm & 2.58624 & 45.3353 & $=1.11442$ & -23.721 & $<0.001^{8 * x}$ \\
\hline & Total & 103.37 & \pm & 6.86973 & 121.776 & $=3.71906$ & -30.721 & $<0.001^{* * 8}$ \\
\hline \multirow{3}{*}{ Third trail } & CPR & 63.917 & \pm & 7.13473 & 80.9118 & \pm 4.09335 & -26.938 & $<0.001^{* * *}$ \\
\hline & AED & 41.417 & \pm & 2.22592 & 45.5824 & \pm .75896 & -23.090 & $<0.001^{* * *}$ \\
\hline & Total & 105.33 & \pm & 7.52428 & 126.494 & $=4.07801$ & -32.235 & $<0.001^{* * *}$ \\
\hline Total practice score & Total & 287.458 & \pm & 14.37622 & 360.7412 & $=9.96105$ & -54.63 & $<0.001^{* * *}$ \\
\hline
\end{tabular}

Highly statistically significant at $\left(\mathrm{p}<0.001^{* *}\right)$ 
Table (4): Relation between students' Total knowledge mean score regarding CPR in both groups andDemographic characteristics.

\begin{tabular}{|c|c|c|c|c|c|c|c|}
\hline \multirow{2}{*}{$\begin{array}{l}\text { Total knowledge } \\
\text { Demographic } \\
\text { characteristics }\end{array}$} & \multicolumn{3}{|c|}{ Control (n=170) } & \multicolumn{2}{|c|}{ Study $(n=170)$} & \multirow{2}{*}{$\begin{array}{l}\text { Independent } \\
\text { t } 1 \text { test } \\
\text { t } 2 \text { test }\end{array}$} & \multirow{2}{*}{$\begin{array}{l}P 1 \text { value } \\
P 2 \text { value }\end{array}$} \\
\hline & Mean & \pm & SD & Mean & $\pm \mathrm{SD}$ & & \\
\hline \multicolumn{8}{|l|}{ Age in years } \\
\hline - $\quad 19-20$ & 19.1140 & + & 3.46093 & 22.1154 & +2.39714 & $\begin{array}{l}2.85 \\
2.85 \\
\end{array}$ & $\begin{array}{l}<0.05^{*} \\
<0.05^{*}\end{array}$ \\
\hline - $\quad$ Female & 18.3517 & + & 4.18584 & 21.8369 & +2.56243 & \multirow{2}{*}{$\begin{array}{l}.847 \\
.880\end{array}$} & \multirow{2}{*}{$\begin{array}{l}>0.05 \\
>0.05\end{array}$} \\
\hline - $\quad$ Male & 18.9600 & + & 3.14219 & 22.1724 & +1.69177 & & \\
\hline \multicolumn{8}{|l|}{ Educational level } \\
\hline - $\quad$ High school graduate & 19.0270 & + & 3.70861 & 21.9426 & +2.62631 & \multirow{2}{*}{$\begin{array}{l}2.49 \\
.476\end{array}$} & \multirow{2}{*}{$\begin{array}{l}<0.05^{*} \\
>0.05\end{array}$} \\
\hline Technical institute & 17.3390 & + & 4.44355 & 21.7708 & +1.88205 & & \\
\hline
\end{tabular}

No statistically significant at $(\mathrm{p}>0.05)$ statistically significant at $\left(\mathrm{p}<0.05^{*}\right)$

t1 \& P1 for control group t $2 \&$ P2 for study group

Table (5): Relation between students' Total practice mean score in study \& control groups and Demographic characteristics.

\begin{tabular}{|c|c|c|c|c|c|c|c|}
\hline \multirow{2}{*}{$\begin{array}{l}\text { Total practice } \\
\text { Demographic } \\
\text { characteristics }\end{array}$} & \multicolumn{3}{|c|}{ Control $(n=170)$} & \multicolumn{2}{|c|}{ Study $(\mathrm{n}=170)$} & \multirow{2}{*}{$\begin{array}{l}\text { Independent } \\
\text { t } 1 \text { test } \\
\text { t } 2 \text { test }\end{array}$} & \multirow{2}{*}{$\begin{array}{l}\mathrm{P} 1 \text { value } \\
\mathrm{P} 2 \text { value }\end{array}$} \\
\hline & Mean & \pm & SD & Mean & $\pm S D$ & & \\
\hline \multicolumn{8}{|l|}{ Age in years } \\
\hline - $\quad 19-20$ & 287.2212 & + & 14.62369 & 361.2462 & +9.86503 & $\begin{array}{l}0.277 \\
1.19\end{array}$ & $>0.05$ \\
\hline - Female & 286.9517 & + & 14.85361 & 361.3404 & +9.72099 & \multirow{2}{*}{$\begin{array}{l}1.10 \\
1.74 \\
\end{array}$} & \multirow{2}{*}{$\begin{array}{l}>0.05 \\
>0.05\end{array}$} \\
\hline - Male & 290.4000 & + & 11.00000 & 357.8276 & +10.76061 & & \\
\hline \multicolumn{8}{|l|}{ Educational level } \\
\hline - High school graduate & 287.6216 & + & 13.49751 & 360.5000 & +10.59179 & \multirow{2}{*}{$\begin{array}{l}0.202 \\
0.502\end{array}$} & \multirow{2}{*}{$\begin{array}{l}>0.05 \\
>0.05\end{array}$} \\
\hline Technical institute & 287.1525 & + & 16.01703 & 361.3542 & +8.21128 & & \\
\hline
\end{tabular}

No statistically significant at $(\mathrm{p}>0.05)$ statistically significant at $\left(\mathrm{p}<0.05^{*}\right)$

t1 \& P1 for control group t 2 \& P2 for study group

Table (6): Correlation between students' total practice score and total knowledge score regarding CPR in both control and study groups

\begin{tabular}{||l|l|l|l|l||}
\hline \multirow{2}{*}{ Items } & \multicolumn{2}{|l|}{ Control group } & \multicolumn{2}{l|}{ Study group } \\
\cline { 2 - 5 } & $\mathbf{R}$ & P value & r & P value \\
\hline $\begin{array}{l}\text { knowledge } \\
\text { Practice }\end{array}$ & 0.563 & $<0.001^{* *}$ & 0.612 & $<0.001^{* *}$ \\
\hline
\end{tabular}

\section{Discussion}

Several educational methods for improving (CPR) have been tried out but both content and methods lack standardization. While, SimMan can be used to meet these demands by creating learning opportunities that are unavailable in clinical practice ${ }^{[5]}$. The CPR is an essential skill for all health care professionals, especially nurses. It can be a lifesaver when applied by a competent and skilled person during resuscitation. The CPR procedure is a coordinated integration of chest compression-induced circulation, rescue breathing and airway management whereby priorities are determined by evidence from literature and practice. Nursing students are instructed to carry out CPR effectively through resuscitation of knowledge and skills in different settings such as the simulation lab for improving learning out comes ${ }^{[8]}$. The present study was conducted to evaluate the effect of educational program for CPR using SimMan versus traditional manikin on $2^{\text {nd }}$ year nursing student's performance at Medical Surgical Nursing Department laboratory- Faculty of Nursing -Benha University.

The present study results show that, there was no statistically significant different regarding Demographic characteristics (age, gender and level of education) in both control and study groups. This result 
isinagreement with ${ }^{[9]}$ who reported that were no statistically significant differences among the participants regarding demographic characteristics as gender and level of education $(p>.05)$. Also this is supported by ${ }^{[10]}$ whoreported that no statistical significant differences between the two groups regarding demographic characteristics $(\mathrm{P}=0.083)$.

Results of the present study showed that mean score of nursing students' knowledge related cardiac arrest, CPR and AED in the study group was higher than the mean score in the control group after the educational program. This may be due to the effectiveness of the educational program implementation.

Regarding the nursing students' knowledge related to CPR, the study revealed that mean score of the nursing students' knowledge related to CPR in the study group was higher than mean score in the control group. This might be due to the using of SimMan as a teaching method was improved restoring and gasping the knowledge for nursing students. This result agreed with ${ }^{[11]}$ who concluded that the using of high fidelity

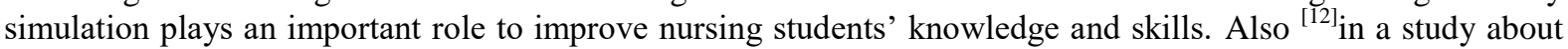
role of SimMan in teaching clinical skills as CPR demonstrated that there was a significant improvement in the students' knowledge and competence to perform CPR. While this was in disagreement with ${ }^{[13]}$ in their study about Comparing two training methods for CPR skill who stated that there is no statistically significant difference between the mean scores of the total questions regarding knowledge assessment for both groups before and after training.

Results of the present study showed that mean score of nursing students' knowledge related AED in the study group was higher than mean score in the control group. This finding was consisted with ${ }^{[14][15]}$ in their studyaboutthe use of Benner's framework in HFS faculty development the bay area simulation collaborative model and they stated that there was a significant difference in favor of the participants in SimMan group on both the acquisition and retention of knowledge and skills over time.

The current study results revealed that an obvious improvement in the total mean knowledge scores of study group using SimMan were documented as compared to control group with highly statistically significant difference. From the researcher points of view that this improvement might be related to the simulation classes using SimMan leading to enhancing and restoring the nursing students' knowledge and given them opportunity for feedback the knowledge so it considers an effective clinical training method for them.This finding is supported by ${ }^{[3]}$ in their study about theuse of high fidelity human simulation to teach physical therapist decisionmaking skills for the intensive care. They found that the nursing students' knowledge and critical thinking improved after the simulation and showed the effectiveness of simulation as a teaching strategy to address nursing knowledge and critical thinking skills.

The researcher points out that the nurse educators should consider the use of high-fidelity simulation as a teaching strategy meets several objectives and can optimize and enhance learning outcomes. So that, SimMan as a teaching modality currently is being used by many nurse educators as an adjunct to a traditional didactic approach in nursing education. This finding is supported by ${ }^{[15]}$ in their study about equivalence testing of traditional and simulated clinical experiences: undergraduate nursing students' knowledge acquisition. Suggested that HFHPS as SimMan was indeed beneficial to both knowledge acquisition and clinical performance of the participants. The results of this study further support the increasing body of knowledge that indicates positive student outcomes related to SimMan.

Based on the present study findings, it is concluded that, the mean score of total practice in the study group during the third trial was more than the mean score of total practice during the first and the second trial in the study group. This may be due to that, SimMan is giving a chance for repetition CPR procedure leading to restoring knowledge and improving the nursing students' practice. This result was in agreement with ${ }^{[16]}$ in their study about a comparative study of defibrillation and CPR performance during simulated cardiac arrest and they found that there was improvement between control group and study group regarding CPR \& AED performance after second and third trail of the observation than after the first trial.

Regarding the nursing students' practice related to CPR, the study revealed that mean score of nursing students' practice related to CPR and AED procedure in the study group was higher than mean score in the control group. This might be due to that SimMan provides reality-based skills training in a safe setting and allows for reflective learning in a positive area. Moreover,SimMan had the ability to repeat scenarios, ensure safe environment, meet clinical skill competence and facilitate psychomotor skills.In the same line ${ }^{[17]}$ in a study aboutInnovative Simulation Strategies in Education who reported that SimMan is a promising learning tool for training nursing students regarding advanced CPR.

The present study findings showed that there were highlystatistically significant differences regarding the mean score of total practice in both control and study groups including CPR and AED procedures. This improvement in nursing students' practice might be due to the fact that the educational program stressed on the practical training to change students' practice using SimMan through adequate scenario, sessions, demonstration and re demonstration, which is needed for achievement of the desired level of practice.According to ${ }^{[18]}$ the use of high-fidelity simulation in CPR training sessions resulted in improved cognitive performance of nursing 
students.Also ${ }^{[19]}$ in a study about "Simulation-based education improves quality of care during cardiac arrest team responses at an academic teaching hospital: a case-control study," found that performance improved significantly after simulator training.

In relation to the nursing students' knowledge and their age, the finding of the current study revealed that there was statistically significant relation, this might be due to the nursing students with advanced age have ability to acquire and restore the knowledge. This result is in congruent with ${ }^{[20]}$ about Impact of a basic life support training program on nurses' knowledge and performance at emergency room and reported that there was significant correlation between age and total basic life support knowledge scores. While this result disagreed with the study conducted by ${ }^{[19]}$ about knowledge of nurses towards CPR in a tertiary care teaching hospital in Nepal and reported that there was no significant association between the total knowledge score and age of the study group.

In relation to nursing students' knowledge and their educational level, the finding of the current study revealed that there was statistically significant relation, this might be due to the nursing students from secondary school have same knowledge about cardiovascular system and respiratory system in their curriculum that may help them to catch knowledge relevant to this issue more than the students from technical health institute and nursing institute or may be due to the students from secondary school were representing the highest percentage in this study.This finding is supported by the study conducted by ${ }^{[21]}$ about effect of CPR training program on nurses' knowledge and practice and showed that there was relation between knowledge and nursing students' socio-demographic characteristics for control and study groups and explained that training program was effective in improving nurses' knowledge and practice related to CPR. This result disagreed with ${ }^{[22]}$ aboutthe role of simulation in teaching pediatric resuscitation and reported thatthere were no statistically significant differences between educational level and baseline knowledge scores between groups.

The current study showed that there were no statistically significant relation between the mean score of students' practice and their demographic characteristics (age, gender and educational level) in both control and study groups with $p>0.05$. This may be due to their lack of awareness that any practical skills required scientific knowledge to enhance their mastering of any skills or their beliefs that the practical experience is not depending on age, gender and educational level; it is acquired process depending on initiation what they observed.In the same line the study conducted by ${ }^{[23]}$ about a comparison of CPR competence between two groups of advanced practice student nurses at a medical training college in Kenya,and reflects that an age, gender and experience had no significant effect on CPR performance between control and study groups.

Concerning thecorrelation between students' total practice and total knowledge score in both control and study groups. The present study cleared that there was positive correlation between the students' total practice score and total knowledge score in both groups. This signified that the knowledgewere influenced on the practice this mean that the nursing students who were having high level of knowledge inducted be having higher level in their practice when using SimMan as a teaching method. Moreover, SimManconsiders an effective and realistic model for integrating the acquired knowledge related to CPR to facilitate practicing of this skill among the nursing students. This finding is in agreement with the result of study conducted by ${ }^{[24]}$ about the effect of CPR training program on nurses knowledge and practice and indicated a positive significant correlation between nurses' knowledge andpractice related to CPR with $p=0.01$.

This study finding is in agreement with the study conducted by ${ }^{[25]}$ aboutan exploration of the relationship between knowledge and performance-related variables in high-fidelity simulation and found that positive correlation between knowledge and practice. However this result is contraindicated with ${ }^{[10]}$ whostated that there was no correlation between the mean scores of total knowledge and skill tests whereas no statistically significant differences in the mean scores between the experimental groups and control groups at $\mathrm{p}>0.05$.

As a final point, the present study showed that there was a highly statistically significant improvement in nursing students' performance level (knowledge and practice) regarding advanced CPR using SimMan versus traditional manikin. So that, SimMan should be becoming rapidly accepted as an advanced teaching tool for nursing educators in all clinical training skills such as CPR.

\section{Conclusion}

In the light of the study finding, it might be concluded that there was a highly statistically significant improvement in the $2^{\text {nd }}$ year nursing students' performance level (knowledge and practice) regarding advanced CPR using SimMan versus traditional manikin

\section{Recommendations}

Based on results of the present study the following recommendations can be suggested:

- Nursing educators should be generalizing using SimMan as a teaching strategy in the nursing students' clinical training versus traditional manikin to enhance students' learning outcomesand achieve a higher performance level, competency and critical thinking namely for all a critical skills. 
- $\quad$ Faculty of nursing at different universities should beready to adopt simulation technology because the use of technology becomes important for training and mastering the nursing students' skills.

- Further researches need to be conducted to evaluate the effect of using SimMan on the nursing students' performance regarding CPR on the actual patients (in the real situations) with cardiac arrest in emergency departments

- Further researches need to be conducted to the evaluate effect of educational program for advanced CPR using SimMan on long-term retention of the nursing students' performance (knowledge \& practice).

- Further studies need to be conducted to evaluate the effect of using traditional manikin for training nursing students' critical skills such as CPR in addition of using video media and electronic teaching strategies on their performance in case of in availability of using SimMan..

\section{Reference}

[1]. Marzouk, T (2015): Effectiveness of simulated delivery room classes on practical achievement and satisfaction of maternity nursing students. Journal of Nursing Education and Practice, 5 (8): 51-59.

[2]. Barton, J., Alsomali, S., Vivienne, N.g., Clarke, S. and Yao, A. (2013): Impact of multidisciplinary team training and high fidelity simulation in critical patient scenarios. The journal of the International Association of Medical Science Educator (IAMSE), 23(3S): 534 .

[3]. Shoemaker, M.J., Riemersma, L. and Perkins, R. (2015): Use of high fidelity human simulation to teach physical therapist decision-making skills for the intensive care setting. CardiopulmPhysTher J, PMCID; 20(1): 13-18.

[4]. Ronald, W. and Robert, J. S. (2014): New frontiers in medical education: Simulation technology at Campbell University School of Osteopathic Medicine. N C Med J, 75(1):59-61.

[5]. American Heart Association (2011): Heart saver CPR and AED Skills Sheet. Available at: www.onlineaha.org. Accessed at 4/9/2013

[6]. Travers, A.H., Rea, T.D., Bobrow, B.J., Edelson, D.P., Berg, R.A., Sayre, M.R., Berg, M.D., Chameides, L., O’Connor, R.E. and Swor, R.A.(2014): American heart association guidelines for cardiopulmonary resuscitation and emergency cardiovascular care, Part 4. Circulation, 122(3): S676-S68.

[7]. Lee, K. (2015): Cardiopulmonary resuscitation: New Concept. TubercRespir Dis (Seoul), 72(5): $401-408$.

[8]. Liaw, S.Y., Rethans, J.J., Scherpbier, A., Piyanee, K.Y. and Rescuing, A. (2014): A simulation-based educational program on recognizing, responding and reporting of physiological signs of deterioration. Resuscitation, 82(9):1224-1230.

[9]. Canlas, J. (2013): Hands-only CPR: An update from the American Heart Association. NASN School Nurse, 24(4), 163-164.

[10]. Al Hadid, L. and Hassan, K.S. (2012): Effect of boost simulated session on CPR competency among nursing students: A Pilot Study. Journal of Education and Practice, 3(16):186-189.

[11]. Mohamed, H.M., Mohamed A.S. and Ismaiel, W.S. (2014): Effectiveness of simulation training on clinical nursing education and competence: randomized controlled trial. International Journal of Advanced Research, 2 (4): 387-393.Available at: http://www.journalijar.com. Accessed at 23/7/2016

[12]. Salah,R.S. (2013): The effect of using simulation based learning versus traditional learning on nursing students' clinical performance of respiratory system. Thesis of doctorate, nursing science in nursing education, faculty of nursing, Alexandria University: 80

[13]. Swamy, M., Bloomfield, T.C., Thoma, R.H., Harnaik, S. and Roger, F. (2013): Role of SimMan in teaching clinical skills to preclinical medical students. BMC Medical Education, 13(20): 133.

[14]. Rezae, P., Safari, A.M., Montazerghaem, H., Reza, H.M., Paknahad, A. and Alavi, A. (2013): Comparing two training methods, traditional CPR skill and distance training at the Red Crescent organization in Hormozgan province. Life Science Journal, 10(9s): 140-145.

[15]. Waxman, K. T. and Telles, C. L. (2010): The use of Benner's framework in high-fidelity simulation faculty development the bay area simulation collaborative model. Clinical Simulation in Nursing, 5: 231-235.

[16]. Schlairet, M. C. and Pollock, J. W. (2012): Equivalence testing of traditional and simulated clinical experiences: undergraduate nursing students' knowledge acquisition. Journal of Nursing Education, 49(1): 43-47.

[17]. EikelandHusebo, S.I., Bjorshol, C.A., Rystedt, H., Friberg, F. and Søreide, E. (2013): A comparative study of defibrillation and cardiopulmonary resuscitation performance during simulated cardiac arrest in nursing. Scand J Trauma ResuscEmerg Med, 2: 2023.

[18]. Aebersold, M., Tschannen, D. and Bathish, M. (2012): Innovative simulation strategies in education.Nurs Res Pract: 7 (6): 212.

[19]. Donoghue, A. J. and Durbin, D. R. (2015): Effect of high-fidelity simulation on Pediatric Advanced Life Support training in pediatric house staff: a randomized trial. PediatrEmerg Care, 25(3): 139-44.

[20]. Wayne, D. B. and Butter, J. (2010): Simulation-based training of internal medicine residents in advanced cardiac life support protocols: a randomized trial. Teach Learn Med, 17(3): 206-210.

[21]. Aly, A. (2010): Impact of a basic life support training program on nurses' knowledge and performance at emergency room. Doctorate thesis, Faculty of nursing, Suez Canal University: 56.

[22]. Parajulee, S. and Selvaraj, V. (2011): Knowledge of nurses towards cardiopulmonary resuscitation in a tertiary care teaching hospital in Nepal. Journal of Clinical and Diagnostic Research, 5(8): 1585-1588.

[23]. Elazazay, H. M., Abdelazez, A. L. and Elsaie, O.A. (2012): Effect of cardiopulmonary resuscitation training program on nurses' knowledge and practice. Life Sci. J, 9(4): 3494-3503.

[24]. Lin, Y. and Cheng, A (2015): The role of simulation in teaching pediatric resuscitation: current perspectives. Adv. Med Educ.Pract, 6: 239-248.

[25]. Kipsang, J. and Bruce, J.C. (2013): Study a comparison of cardiopulmonary resuscitation competence between two groups of advanced practice student nurses at a medical training college in Kenya. Africa Journal of Nursing and Midwifery, 13 (2): $103-118$

[26]. Hauber, R. P., Cormier, E. and Whyte, J. (2015): An exploration of the relationship between knowledge and performance-related variables in high-fidelity simulation: Designing instruction that promotes expertise in practice. Nursing Education Perspectives, 31(4): 242-246. 